\title{
Recurrent Adult Burkitt Lymphoma
}

National Cancer Institute

\section{Source}

National Cancer Institute. Recurrent Adult Burkitt Lymphoma. NCI Thesaurus. Code C8159.

The reemergence of adult Burkitt lymphoma after a period of remission. 